\title{
O impacto da implantação do FUNDEF na educação infantil no município de Campo Grande/MS (1997 a 2000)
}

The implementation impacts of FUNDEF in infant
education in Campo Grande/MS, , Brazil [1997-2000]

\author{
Maria Dilnéia Espíndola Fernandes ${ }^{1}$ \\ Francielli de Souza Lourenço ${ }^{2}$
}

\section{RESUMO:}

O objetivo deste trabalho foi desvelar os impactos que o Fundo de Manutenção e Desenvolvimento do Ensino Fundamental e de Valorização do Magistério (Fundef), regulamentado pela Lei n. 9.424/1996, causou na educação infantil no município de Campo Grande, no período imediatamente posterior à sua implantação, entre 1997 e 2000 (gestão do prefeito André Puccinelli). Ressalte-se que o Fundef determinou a focalização dos recursos públicos para manutenção e desenvolvimento do ensino no ensino fundamental, embora pela legislação educacional vigente a educação infantil constitui-se na primeira etapa da educação básica, sob responsabilidade do governo municipal. Para tanto foram analisadas a legislação educacional em âmbito federal, estadual e municipal, dados estatísticos populacionais e educacionais, bem como os balanços de contas de governo do município de Campo Grande. De fato, a educação infantil em Campo Grande, historicamente, foi atendida tanto pelo estado como pelo município. Com a vigência do Fundef e com a implantação do regime de ciclos, o governo estadual, contudo, se retirou totalmente desse atendimento. Os resultados da pesquisa demonstraram que houve redução de matrículas e de recursos para a educação infantil no município no período, à medida que o Fundef subvinculou $60 \%$ dos recursos destinados à manutenção e desenvolvimento do ensino para a etapa fundamental, aumentando significativamente a demanda reprimida para a educação infantil.

Palavras-Chave: Política Educacional; Financiamento da Educação Infantil; Fundef; Educação Infantil em Campo Grande.

1 Doutora em Educação pela Universidade Estadual de Campinas (UNICAMP) e Professora Adjunta da Universidade Federal de Mato Grosso do Sul do Programa de Pós-Graduação em Educação - Cursos Mestrado e Doutorado - e do Departamento de Educação/CCHS. E-mail: mdilneia @uol.com.br.

2 Acadêmica do Curso de Pedagogia do Departamento de Educação/CCHS da Universidade Federal de Mato Grosso do Sul e professora da educação básica. 


\section{ABSTRACT:}

The objective of this work is to unveil the impacts of the fund for the Maintenance and Development of Fundamental Education and the Valorization of Teaching [Fundef], regulated by the Law \#9424/1996, caused in infant education in the municipality of Campo Grande during the period immediately following its implantation, between the years 1997 and 2000 [during the Mayor André Pucinelli's tenure]. It is emphasized that the Fundef determined the focalization of public funds for the maintenance and development of schooling in fundamental education, although local legislation in vigour had infant education constituted as the first step of basic education, un the municipal government's responsibility to this end, educational legislation on the municipal, state and federal levels was analyzed, along with statistical data on population and education, as well as account balance-sheets if the municipal government of Campo Grande. In effect, infant education in Campo Grande was attended to by the state as well as the municipality. With the effectivity of the Fundef, and with the implantation of the cyclical regime, the state government, however, stopped all financial support. Research results showed that there was a reduction of the matriculations and resources for infant education in the municipality during the period, to the extent that the Fundef subliinked $60 \%$ of the resources destined to the maintenance and development of schooling of the fundamental level, sensitively raising the repressed demand for infant education.

Keywords: Educational Policy; Financing of Infant Education; Fundef; Infant Education in Campo Grande [MS].

\section{Introdução}

A educação infantil, com a promulgação da Constituição Federal de 1988, constituiu-se como a primeira etapa da educação básica brasileira, inaugurando com isso a ampliação efetiva de um novo conceito para a educação do nascimento aos 17 anos de idade, para o conjunto da população brasileira.

Diante disso, o artigo 211 da Constituição Federal afirma que "os municípios atuarão prioritariamente no ensino fundamental e na educação infantil" e o artigo 212 instituiu que, para o financiamento do ensino público, "a União aplicará anualmente, nunca menos de dezoito, e os Estados, o Distrito Federal e os Municípios vinte e cinco, no mínimo da receita resultante de impostos mais as transferências intergovernamentais provenientes".

Estas disposições foram normatizadas pela Lei de Diretrizes e Bases da Educação Nacional (Lei n. ${ }^{\circ}$ 9.394), aprovada em 1996, durante o governo do presidente Fernando Herinque Cardoso (FHC), cuja gestão tinha como premissa de que, na Educação "[...] os recursos já existentes são suficientes, cabendo apenas otimizar a sua utilização." (PINTO, 2002, p. 1).

Vale ressaltar, contudo que, quatro dias antes da aprovação da Lei n. ${ }^{\circ}$ 9.394/1996, foi aprovado o Fundo de Manutenção e Desenvolvimento do Ensino Fundamental e de Valorização do
Magistério (FUNDEF), que foi instituído pela Emenda Constitucional n. ${ }^{\circ}$ 14, de 12 de setembro de 1996, alterando o artigo 60 do Ato das Disposições Constitucionais Transitórias, (ADCT), e regulamentado pela Lei n. ${ }^{\circ}$ 9.424, de 24 de dezembro de 1996 e pelo Decreto Federal n. ${ }^{\circ} 2.264$, de 27 de junho de 1997, com prazo de vigência de 10 anos. O Fundef é um fundo de natureza contábil proveniente de $15 \%$ das contribuições dos impostos vinculados: Imposto sobre operações relativas à Circulação de Mercadorias e Serviços de Transporte Interestadual e de Comunicações (ICMS); Fundo de Participação dos Estados (FPE); Fundo de Participação dos Municípios (FPM); Imposto Sobre Produtos Industrializados (IPI) Exportação e pela Lei Complementar n. ${ }^{\circ}$ 87/1996, também conhecido como Lei Kandir.

Os recursos do Fundef são distribuídos, em cada unidade federada, entre o governo estadual e os governos municipais, com base no número de alunos matriculados nas respectivas redes de ensino fundamental, de acordo com os dados do censo escolar repassados, automaticamente, para contas únicas e específicas dos governos estaduais, do Distrito Federal e dos municípios, vinculados ao Fundo (art. $3^{\circ}$ ). Dessa forma, - Banco do Brasil retira 15\% dos recursos provenientes dessas contribuições, depositandoos na conta do Fundo. 
O cálculo de distribuição dos recursos do FUNDEF é feito sobre o número de matrículas do ano anterior, acrescentando-se uma estimativa de novas matrículas feita pelo MEC (Decreto 2.264/1997). Essa estimativa, de forma geral, não tem correspondido ao número real de novas matrículas, ficando estas matrículas sem recursos do Fundo.

O valor mínimo nacional por aluno-ano foi fixado em $\mathrm{R} \$ 315,00$ (trezentos e quinze reais) nos anos de 1998 (Decreto Presidencial n. ${ }^{\circ}$ 2.440/1997) e 1999 (Decreto Presidencial n. ${ }^{\circ}$ 2.935/1999). No ano 2000, o valor foi de $\mathrm{R} \$ 333,00$ (trezentos e trinta e três reais) para a $1^{a}$ até $4^{a}$ série; e $\mathrm{R} \$ 349,65$ (trezentos e quarenta e nove reais e cinquenta e cinco centavos), para a $5^{a}$ até a $8^{a}$ série (Decreto Presidencial n. ${ }^{\circ} 3.326 / 1999$ ).

De acordo com a Lei n. ${ }^{\circ}$ 9.424/1996, a União complementará os recursos do Fundef sempre que, no âmbito de cada estado e do Distrito Federal, não alcançar o valor mínimo por aluno definido nacionalmente (art. $6^{\circ}$ ), sendo que os recursos do Fundo devem ser gastos, exclusivamente, com o ensino fundamental. Além disso, o percentual mínimo de 60\% deve ser empregado para a remuneração dos profissionais em efetivo exercício do magistério no ensino fundamental público (art. $7^{\circ}$ ). Os $40 \%$ restantes podem ser gastos com qualquer despesa do ensino fundamental, desde que realizadas com a manutenção e o desenvolvimento do ensino, conforme o artigo 70, incisos I a VIII da Lei de Diretrizes e Bases da Educação Nacional, n. ${ }^{\circ}$ 9.394/96.

Essa dinâmica de priorização de recursos e rateamento, tendo como critério as matrículas do ensino fundamental, implicaram consequências nem sempre equacionadas para as outras etapas da educação básica, como argumentou Davies (1999, p.17):

0 Fundef contribui para enfraquecer e desarticular 0 sistema de ensino, uma vez que, segundo a Lei 9.424 , as matrículas da educação infantil, de jovens e adultos (supletivo) e do ensino médio não são consideradas para efeitos de redistribuição dos recursos. Como só as matrículas no ensino fundamental regular valem para a obtenção de recursos do Fundef, as autoridades tenderão a privilegiar tais matrículas e deixar de lado as dos demais níveis de ensino.
Esse mesmo autor aponta que os efeitos da implantação do FUNDEF sobre a Educação Infantil foram praticamente imediatos:

Os efeitos do Fundef sobre outros níveis emodalidades de ensino já se fizeram sentir em 1998. Segundo avaliação divulgada pela Undime (União Nacional dos Dirigentes Municipais de Educação) em 16 de Março de 1999, houve uma diminuiçã̃o da oferta de vagas na Educação Infantil [...] (DAVIES, 1999, p.18)

E ainda conforme apontou Abreu:

Em Municípios que ofereciam quase que exclusivamente atendimento em creches e préescolas e que, em decorrência, perdem recursos com o FUNDEF - é o caso da ampla maioria dos Municípios paulistas -, as Prefeituras passam a contar com um volume bastante inferior de recursos financeiros para manter a rede de instituições de educação infantil que mantinham antes da implantação do FUNDEF (2004, p. 10).

Sabe-se que não é o caso do município de Campo Grande, pois este desde 1988 vem apresentando uma demanda para matrículas na educação infantil sempre inferior à oferta. Por isso mesmo busca-se neste trabalho desvelar qual a natureza dos impactos que a implantação do FUNDEF causou na educação infantil no município de Campo Grande, no período imediatamente posterior à sua implantação, entre 1997 e 2000 (gestão do prefeito André Puccinelli). O ano de 1997 justifica-se em razão da dinâmica apresentada pelas matrículas às vésperas da implantação do FUNDEF, cobrindo o período de mais três anos, com o objetivo de sistematizar os dados coletados quando tais dados já apontavam o comportamento delineado pelas matrículas e recursos disponíveis para a educação infantil no município.

Assim, este trabalho sustenta-se na análise documental (legislação educacional em âmbito federal, estadual e municipal) e dados estatísticos extraídos do Instituto Brasileiro de Geografia e Estatística (IBGE), do Instituto Nacional de Estudos Pedagógicos e Pesquisas Educacionais Anísio Teixeira (INEP) e do Ministério da Educação (MEC).

De fato, Menga e André (1986, p. 1) afirmam que, metodologicamente, um trabalho sustentase "no confronto entre dados sobre determinado assunto e o conhecimento acumulado a respeito 
[...] a partir do estudo de um problema, que ao mesmo tempo desperta o interesse do pesquisador e limita sua atividade de pesquisa a uma porção de saber".

Diante disso, o objetivo deste trabalho foi discutir como o financiamento da educação infantil materializou o direito a esta etapa da educação básica brasileira no município de Campo Grande no período de 1997 a 2000, à medida que o FUNDEF impôs novas regras no trato orçamentário e contábil, por um lado. E redefiniu as prioridades do regime de colaboração entre as esferas subnacionais no que tange à política de financiamento, por outro, subsumindo a relativa autonomia no exercício da política educacional destas esferas ao domínio do governo central.

É certo, a bem da verdade, que a autonomia relativadasesferassubnacionaistemsidoexercida no campo do financiamento para manutenção e desenvolvimento do ensino em uma lógica em que a esfera executiva do Estado toma como limite máximo aquilo que a legislação em nível federal estabeleceu como limite mínimo. Isso tem acontecido com a vinculação constitucional de recursos para manutenção e desenvolvimento do ensino, salvo raras exceções.

Tais exceções se expressaram em termos legais nas Constituições Estaduais e Leis Orgânicas Municipais do início dos anos 1990, após a promulgação da Constituição Federal de 1988, como foi o caso de alguns estados e municípios. Entre as esferas subnacionais que procederam dessa forma estava o e Estado de Mato Grosso do Sul e o município de Campo Grande - ambos vincularam 30\% da receita de impostos para manutenção e desenvolvimento do ensino em seus respectivos aparatos jurídicolegais. Igualmente voltaram atrás em 1997, revendo tais dispositivos com a aprovação de emendas à legislação pertinente às vésperas da implantação do FUNDEF, remetendo a vinculação constitucional de seus recursos ao que instituía a legislação em âmbito federal, de modo que se retiraram de um patamar de recursos que possibilitaria ampliar o direito à educação básica como ação do Estado.

De fato, historicamente o atendimento às crianças de 0 a 6 anos no município de Campo
Grande ocorreu por meio de programas sociais desencadeados pela Secretaria de Assistência Social. Tais programas, cabe ressaltar, foram realizados muito mais em razão da indução por parte da esfera federal (União) no bojo do processo de industrialização e urbanização do país do que propriamente como fruto da iniciativa local. Assim, as iniciativas locais foram pontuais e fragmentadas até a promulgação da Constituição Federal de 1988. Até então o atendimento à criança de 0 a 6 anos no município era quase exclusivamente feito pelos programas oriundos da extinta Legião Brasileira de Assistência (LBA).

De forma que, em 1998, ano de implantação do FUNDEF, principalmenteoatendimentoemcreche, ainda era feito pela Secretaria de Assistência Social do município, bem como um número expressivo de crianças entre 5 e 6 anos também. $\mathrm{Na}$ verdade, como os dados apresentados neste trabalho confirmaram, a educação infantil, como primeira etapa da educação básica, nunca esteve entre as prioridades de atendimento educacional do município.

\section{A demanda para a educacão infantil no Estado de Mato Grosso do Sul (1997 a 2000)}

Para se observar o atendimento à criança de 0 a 6 anos em Campo Grande, verificou-se antes a necessidade desse atendimento no estado, à medida que, por um lado, até 1997 o estado atendeu parcelas dessa população e, por outro, a legislação educacional em vigor estabeleceu novas bases para o regime de colaboração entre os entes federados. Diante disso, distinguir qual esfera federativa estaria cumprindo sua parte no regime de colaboração tornou-se um imperativo para a verificação do exercício da política educacional para a educação infantil.

A população de 0 a 6 anos de idade em Mato Grosso do Sul pode ser observada na tabela 1:

Tabela 1 - População de 0 a 6 anos no Estado de Mato Grosso do Sul (1997- 2000)

População de 0 a 6 anos de idade em Mato Grosso do Sul

\begin{tabular}{c|c|c|r}
1997 & 1998 & 1999 & 2000 \\
\hline 284.531 & 285.995 & 285.267 & 291.977
\end{tabular}

FONTE: Censo (2000) e PNAD (1997, 1998, 1999). Foram utilizados os números do PNAD nos anos de 1997 a 1999, em razão do Censo Populacional ser uma base de dados 
coletada, atualizada e publicada a cada decênio.

A partir da tabela 1 e do gráfico 1 constatouse que, no período de 1997 a 2000, a população infantil de 0 a 6 anos no estado teve um crescimento de 2,6\%. Já no período entre 1998 e 1999 houve uma redução de 728 crianças nesse universo populacional, e em 2000, o crescimento foi de 2,3\%.

Gráfico 1 - População infantil de 0 a 6 anos no Estado de Mato Grosso do Sul (1997-2000)

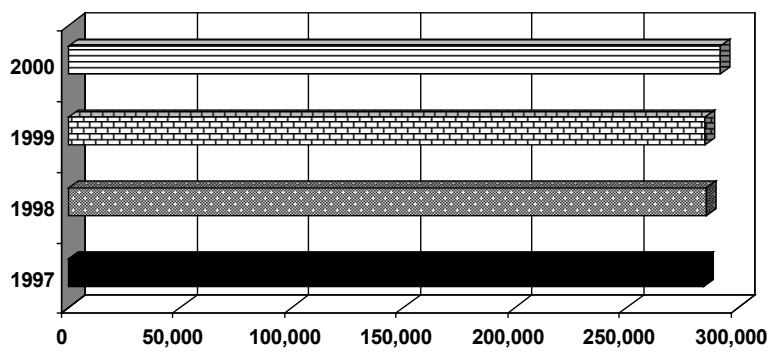

FONTE: Gráfico elaborado a partir de Censo (2000) e PNAD (1997, 1988, 1999).

A partir da tabela 2, ficou visível a queda das matrículas na pré-escola no estado em 1998 ano de implantação do FUNDEF. A redução do total de matrìculas na pré-escola de 1997 para 1998 foi de 20,85\%. Esta queda de matrículas no estado demonstrou uma realidade nacional, como apontou o Relatório da Undime: "em apenas um ano de funcionamento, os efeitos perversos do FUNDEF na Educação Infantil já se fazem sentir. Houve uma diminuição de vagas para este segmento" (UNDIME, 1999, p. 04).

Tabela 2 - Matrícula na educação infantil por dependência administrativa no Estado Mato Grosso do Sul ${ }^{\star}$

\begin{tabular}{|c|c|c|c|c|c|c|}
\hline \multicolumn{3}{|c|}{ Ano } & 1997 & 1998 & 1999 & 2000 \\
\hline \multirow{8}{*}{ 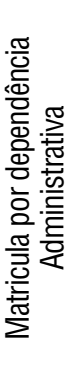 } & \multirow{2}{*}{ Estadual } & ${ }^{*}$ Creche & --- & --- & 1.030 & 1.211 \\
\hline & & Pré-escola & 13.233 & 1.699 & 1.913 & 2.023 \\
\hline & \multirow{2}{*}{ Municipal } & Creche & ---- & - & 8.932 & 9.585 \\
\hline & & Pré-escola & 21.774 & 24.186 & 28.998 & 31.530 \\
\hline & \multirow{2}{*}{ Privada } & Creche & ---- & --- & 2.454 & 2.898 \\
\hline & & Pré-escola & 13.347 & 12.383 & 11.755 & 12.664 \\
\hline & \multirow{2}{*}{ Total Geral } & Creche & --- & --- & 12.416 & 13.694 \\
\hline & & Pré-escola & 48.345 & 38.268 & 42.666 & 46.217 \\
\hline
\end{tabular}

*Observou-se que os dados das creches não eram computados nas estatísticas educacionais até 1999, desta forma verificaram-se os dados sobre a pré-escola entre 1997

e 1999, que recebia apenas as crianças de 4 a 6 anos

Contudo, quando foram verificadas apenas as matrículas das redes municipais observouse um ritmo de crescimento intenso. No período de 1997 a 2000 esse crescimento foi de 44,8\%, como mostra o gráfico 2 .
Gráfico 2 - Matrícula da pré-escola por dependência administrativa no Estado Mato Grosso do Sul

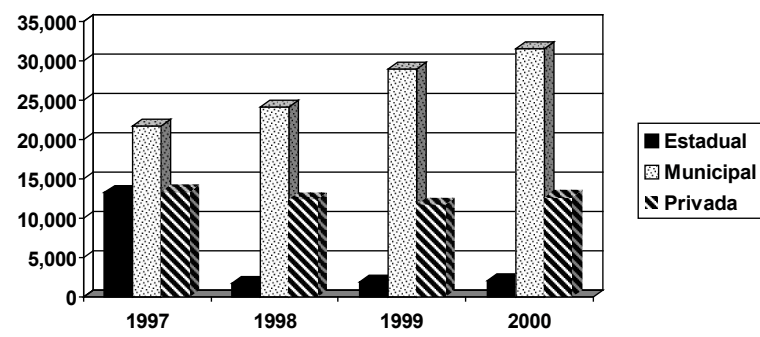

FONTE: INEP/Censo Escolar, 1997-2000.

Asmatrículas das redes municipais estavamaté 2000 em processo de expansão, já as matrículas na rede privada ficaram estabilizadas. Esse aumento refletiu o movimento de descentralização dos sistemas de ensino, alavancado pela forma de rateio do Fundo. Outro fator de crescimento dos números entre 1998 e 1999 nos municípios foi causado pela absorção das matrículas de instituições vinculadas à Assistência Social nas estatísticas educacionais. Dessa forma, foram incorporadas crianças que já eram atendidas, porém não contabilizadas, o que caracterizou um falso crescimento (ROSA, 2005).

De forma que em 1998 obteve-se uma diminuição de $87,17 \%$ do número das matrículas estaduais, o que demonstrou a retirada do estado nesse atendimento, como demonstra o gráfico 3.

Gráfico 3 - Matrículas da pré-escola na rede estadual de ensino de Mato Grosso do Sul (1997 a 2000)

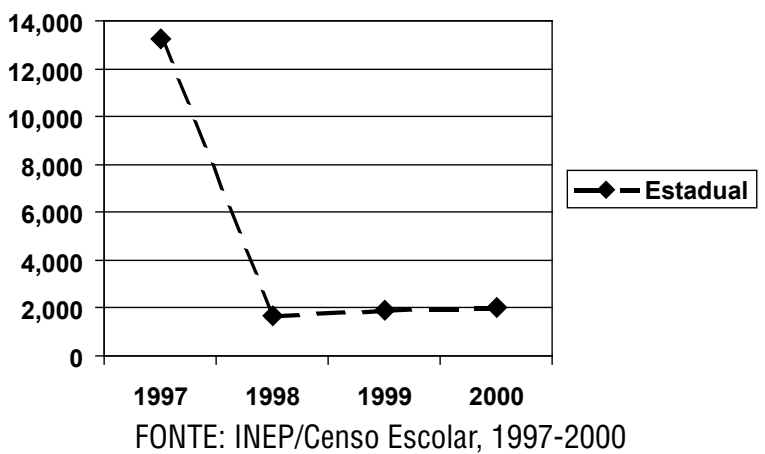

Não obstante estes dados, a educação infantil, conforme disposto pela Constituição Federal de 1988, seria uma prioridade dos municípios. Os dados apresentados até aqui, contudo, mostram que o regime de colaboração e o caráter supletivo também previsto na legislação infraconstitucional ainda estão na pauta da agenda da política educacional. De forma que o texto do legislador abriu precedentes para interpretações dúbias entre a concepção e a prática da política educacional, 
como reconheceu este documento produzido pela Secretaria de Estado de Educação:

Mas foi a partir da interpretação das leis e do entendimento estabelecido pelo financiamento que, em 1998, Mato Grosso do Sul, iniciou um processo de desativação da pré-escola na rede estadual de ensino e, consequentemente, uma municipalização da Educação Infantil, sem discussão, organização e previsão dos impactos dessa desativação, criando vários impasses tanto para o Estado, quanto para os municípios, particularmente para Educação Infantil (MATO GROSSO DO SUL, 2006, p. 13).

Uma das razões de Estado para esta desativação foi a implantação do Regime de Ciclos no ensino fundamental, que incorporou as crianças de 6 anos nesta etapa da educação básica. Dessa forma, as matrículas dessas crianças estariam sendo contabilizadas pelo Fundef. Enquanto isso, parcelas significativas de crianças de 4 e 5 anos ficaram sem atendimento tanto pela rede estadual quanto pela rede municipal de ensino.

No cruzamento entre os dados quantitativos da população infantil com o número de matrículas observou-se o percentual de demanda reprimida. Nesse cruzamento utilizaram-se os dados, especificamente do Censo $(1991,2000)$ e da contagem Populacional (1996), ambos do IBGE. Dessa forma o recorte temporal situou-se nos anos de 1991, 1996 e 2000.

Tabela 3 - Demanda reprimida na pré-escola no Estado de Mato Grosso do Sul (1991, 1996 e 2000)

\begin{tabular}{|c|c|c|c|c|c|}
\hline \multicolumn{3}{|c|}{ Ano } & 1991 & 1996 & 2000 \\
\hline \multirow{3}{*}{ 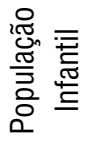 } & \multicolumn{2}{|c|}{0 a 6 anos } & 295.128 & 286.702 & 291.977 \\
\hline & \multicolumn{2}{|c|}{0 a 3 anos } & 168.286 & 163.105 & 161.110 \\
\hline & \multicolumn{2}{|c|}{$4 \mathrm{a} 6$ anos } & 126.842 & 123.597 & 130.867 \\
\hline \multirow{2}{*}{ 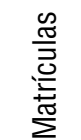 } & \multicolumn{2}{|c|}{ Creche } & --- & --- & 13.694 \\
\hline & \multicolumn{2}{|c|}{ Pré-Escola } & 35.675 & 49.002 & 46.217 \\
\hline \multirow{6}{*}{ 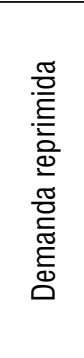 } & \multirow{2}{*}{$\begin{array}{l}0 \text { a } 3 \\
\text { anos }\end{array}$} & $\begin{array}{c}n^{\circ} \\
\text { absol. }\end{array}$ & --- & --- & 147.416 \\
\hline & & $\%$ & --- & --- & $91 \%$ \\
\hline & \multirow{2}{*}{$\begin{array}{l}4 \text { a } 6 \\
\text { anos }\end{array}$} & $\begin{array}{c}n^{\circ} \\
\text { absol. }\end{array}$ & 91.167 & 74.595 & 84.650 \\
\hline & & $\%$ & $71,87 \%$ & $60,35 \%$ & $64,68 \%$ \\
\hline & \multirow{2}{*}{$\begin{array}{l}0 \text { a } 6 \\
\text { anos }\end{array}$} & $\begin{array}{c}n^{\circ} \\
\text { absol. }\end{array}$ & --- & --- & 232.066 \\
\hline & & $\%$ & --- & --- & $79,48 \%$ \\
\hline
\end{tabular}

FONTE: Construído para o presente trabalho a partir de dados: Estatística/SUPAE/SED-MS e IBGE (censo 1991e 2000, contagem populacional 1996).

A demanda reprimida na pré-escola em 1991 era de 71,87\%. Em 1996 houve uma diminuição da demanda reprimida, que contabilizava $60,35 \%$. Estes índices demonstraram um movimento de expansão da pré-escola entre 1991 e 1996. Observou-se que aumentaram as matrículas, contudo a população dessa faixa etária diminuiu em razão de que a tendência nacional de crescimento vegetativo da população também vem sendo percebida tanto no estado quanto no município de Campo Grande. Como mostra a tabela 3, de 1991 a 1996, são 8.426 crianças a menos. Já quando se observou o período entre 1996 e 2000, a demanda reprimida aumentou 4,33\%, e 5.275 crianças a mais demandaram por educação infantil.

Em 1996, das 123.597 crianças entre 4 e 6 anos, 49.002 estavam matriculadas na préescola. Isto significou que 74.595 crianças não foram atendidas. Em 2000, das 130.867 crianças desta faixa etária, 84.650 estiveram fora da préescola. Situação que pode ser visualizada nos gráficos 4 e 5 :

Gráfico 4 - Demanda reprimida na pré-escola no Estado de Mato Grosso do Sul em 1996

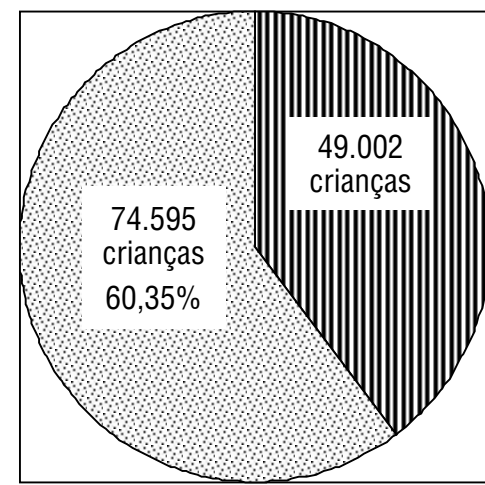

III Demanda atendida

Demanda

Reprimida

FONTE: Gráfico elaborado a partir de dados da Coordenadoria de Estatística /SUPAE/SED-MS e IBGE (censo 2000, contagem populacional 1996).

\section{Gráfico 5 - Demanda reprimida na pré-escola no Estado de} Mato Grosso do Sul em 2000
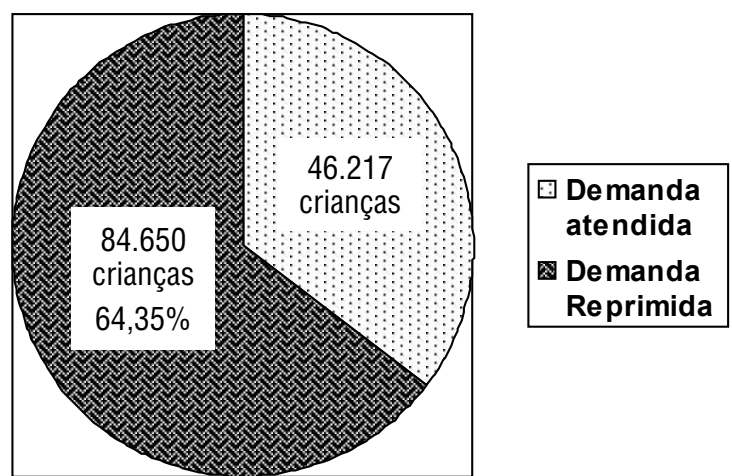

FONTE: Gráfico elaborado a partir de dados da Coordenadoria de Estatística/SUPAE/SED-MS e IBGE (censo 1991e 2000, contagem populacional 1996). 
Em 2000, já foi possível analisar impactos sobre a educação infantil incorporando os dados das crianças de até 3 anos. Assim, a demanda reprimida representou $79,48 \%$ na faixa de 0 a 6 anos. O mais alarmante foi o índice de $90,1 \%$ de demanda reprimida nas creches.

Gráfico 6 - Demanda reprimida na educação infantil no Estado de Mato Grosso do Sul em 2000

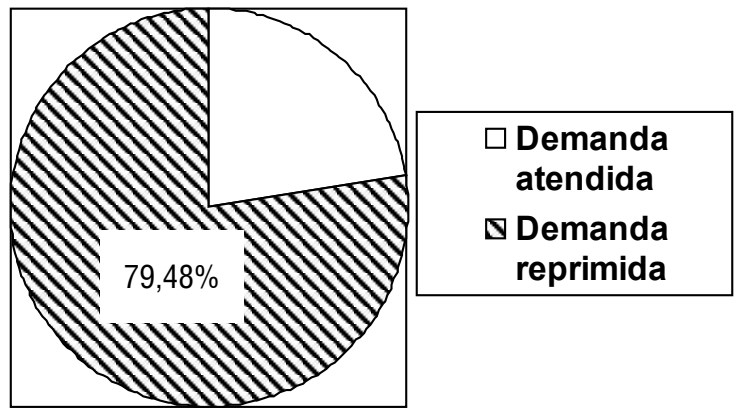

FONTE: Gráfico elaborado a partir de dados da Coordenadoria de Estatística/SUPAE/SED-MS e IBGE (censo 1991e 2000, contagem populacional 1996).

Gráfico 7 - Demanda reprimida em Creche no Estado de Mato Grosso do Sul em 2000

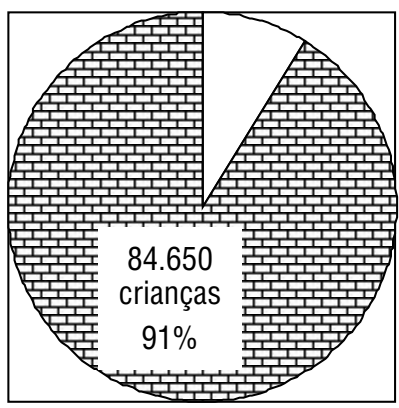

\begin{tabular}{|c|}
\hline Demanda \\
atendida \\
$\square$ Demanda \\
reprimida \\
\hline
\end{tabular}

FONTE: construído a partir de dados da Coordenadoria de Estatística/SUPAE/SED-MS e IBGE (censo 1991e 2000, contagem populacional 1996).

Isso significou que de cada 100 crianças de 0 a 6 anos, apenas 21 frequentaram a educação infantil em 2000. Agora, quando analisada somente a população infantil de 0 a 3, percebeu-se que de cada 100 crianças, apenas 9 frequentaram creches.

\section{A educacãa infantil no município de Campo Grande (1997-2000)}

Assim como na análise sobre o atendimento pelo estado, iniciou-se aqui pelos dados quantitativos da população infantil de 0 a 6 anos no município de Campo Grande. Neste caso também, utilizaram-se os dados do IBGE, cujo recorte foi os anos de 1991, 1996 e 2000.

Tabela 4 - População de 0 a 6 anos no município de Campo Grande $(1991,1996$ e 2000)

\begin{tabular}{|c|c|c|c|}
\hline $\begin{array}{l}\text { População de 0 a 6 anos no } \\
\text { município de Campo Grande }\end{array}$ & 1991 & 1996 & 2000 \\
\hline 0 a 3 anos & 47.093 & 46.956 & 46.956 \\
\hline 4 a 6 anos & 35.530 & 36.011 & 38.281 \\
\hline Total & 82.623 & 82.967 & 85.237 \\
\hline
\end{tabular}

FONTE: IBGE (censo 1991e 2000, contagem populacional 1996).

A população infantil de até 3 anos no município de Campo Grande sofreu uma pequena diminuição entre os anos de 1991 a 2000, de 0,30\%. Já a população de 4 a 6 anos estava em ritmo de crescimento de 7\% no período de 1996 a 2000.

No caso do total de crianças de 0 a 6 anos, em 1991 eram 82.623; em 1996, 82.967, e 85.237 crianças em 2000. Entre 1991 e 2000, o crescimento foi de 3,16\%. Entre 1996 e 2000, o crescimento da população infantil do município de Campo Grande acompanhou o índice de crescimento do estado no mesmo período e permaneceu no patamar de 2,7\%.

Gráfico 8 - População de $\mathbf{0}$ a 6 anos no município de Campo Grande (1991, 1996 e 2000)

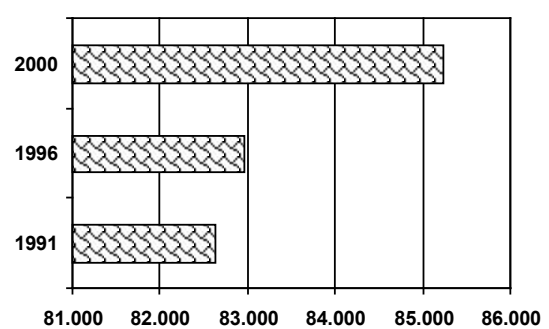

G População $\operatorname{lnf}$ anti

FONTE: IBGE (censo 1991e 2000, contagem populacional 1996)

No cruzamento entre os dados das matrículas na pré-escola com as matrículas da $1^{\text {a }}$ série do ensino fundamental em 1999 e 2000, como exposto na tabela 5, observou-se que entre 1999 e 2000 houve uma diminuição de 406 matrículas na pré-escola no município de Campo Grande. Ao analisar as matrículas municipais, vemos uma diminuição de 909 matrículas na pré-escola e na primeira série do ensino fundamental, um aumento de 842 matrículas.

Tabela 5 - Matrículas na pré-escola e na primeira série do ensino fundamental na rede municipal de ensino de Campo Grande em 1999 e 2000

\begin{tabular}{|c|c|c|c|c|c|}
\hline Ano & Série & Estadual & Municipal & Privada & Total \\
\hline \multirow{2}{*}{ 용 } & $\begin{array}{c}\text { Pré- } \\
\text { escola }\end{array}$ & 1.913 & 6.644 & 6.031 & 14.588 \\
\cline { 2 - 6 } & $1^{\text {a }}$ Série & 7.959 & 8.116 & 2.820 & 18.895 \\
\hline \multirow{2}{*}{ ○ } & $\begin{array}{c}\text { Pré- } \\
\text { escola }\end{array}$ & 1.971 & 5.735 & 6.476 & 14.182 \\
\cline { 2 - 6 } & $1^{\text {a }}$ Série & 6.845 & 8.958 & 2.741 & 18.544 \\
\hline
\end{tabular}

FONTE: construída para o presente trabalho a partir de dados do INEP/COEST/DGAF/SED-MS. 
Quando observamos os números da primeira série do ensino fundamental em 2000, ficou expressiva a presença do atendimento municipal. Mais um indício da priorização do ensino fundamental na rede municipal de ensino.

Outro índice relevante foi o crescimento de matrículas da pré-escola na rede privada. Em 2000, essa rede deteve 445 matrículas a mais que 1999 - um aumento de 6,9\%. No ano de 2000, as instituições privadas receberam na pré-escola 741 crianças a mais que o município, como pode se observar no gráfico 9.

Davies (1999) indicou que uma das consequências do FUNDEF seria o abandono desta etapa da educação básica pela rede pública, situação que poderia ampliar o mercado das escolas particulares, o que de fato se constatou no município de Campo Grande, de acordo com os dados elencados abaixo.

\section{Gráfico 9 - Matrículas na pré-escola e na primeira série na rede municipal e na rede privada no município de Campo Grande (1999-2000)}

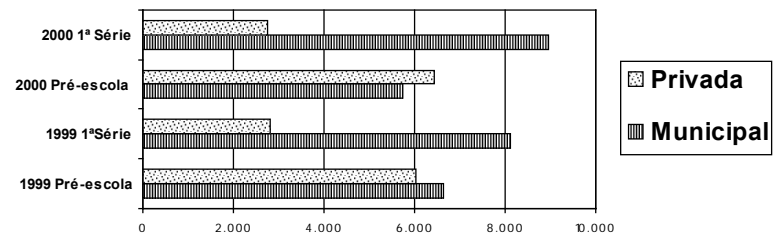

FONTE: construído para o presente trabalho a partir de dados do INEP/COEST/DGAF/SED-MS

Outra questão pertinente foi a redução de matrículas na pré-escola na rede estadual no município de Campo Grande. Em 1997 eram 4.469 matriculas que se reduziram a 1.616, ou seja, uma redução de 63,8\%. Como se observou anteriormente, o Estado de Mato Grosso do Sul com a Resolução/SED n. ${ }^{\circ}$ 1.222/1998 implantou o sistema de ciclos em 1998 e desativou as salas de pré-escolas. Esta retirada acelerada do estado na educação infantil é comentada por Didonet:

Os estados estão fazendo o papel de "Pilatos no Credo" - lavando as mãos. Fechar préescolas, transferir as responsabilidades para os municípios, dizer que não é tarefa deles é, no mínimo, interpretação errada do dispositivo constitucional que distribui competências e responsabilidades entre as esferas administrativas. No mínimo, seria necessário um plano de transferências, com acordo mútuo, um contrato de passagem progressivo do atendimento estadual para 0 município (1999, p.3).

Tabela 6 - Matrículas na educação infantil por dependência administrativa no município de Campo Grande (1997, 1998, 1999 e 2000)

\begin{tabular}{|c|c|c|c|c|c|}
\hline \multicolumn{2}{|c|}{$\begin{array}{c}\text { Matrícula por } \\
\text { Dependência } \\
\text { Administrativa }\end{array}$} & 1997 & 1998 & 1999 & 2000 \\
\hline \multirow{2}{*}{ Estadual } & Creche & ----- & ----- & 1.031 & 1.211 \\
\hline & $\begin{array}{c}\text { Pré- } \\
\text { escola }\end{array}$ & 4.469 & 1.616 & 1.913 & 1.971 \\
\hline \multirow{2}{*}{ Municipal } & Creche & ----- & ----- & 2.327 & 2.637 \\
\hline & $\begin{array}{c}\text { Pré- } \\
\text { escola }\end{array}$ & 3.002 & 3.265 & 6.644 & 5.735 \\
\hline \multirow{2}{*}{ Privada } & Creche & ----- & ----- & 1.392 & 1.748 \\
\hline & $\begin{array}{c}\text { Pré- } \\
\text { escola }\end{array}$ & 6.708 & 6.449 & 6.031 & 6.477 \\
\hline \multirow{2}{*}{ Total Geral } & Creche & ----- & ----- & 4.749 & 5.569 \\
\hline & $\begin{array}{l}\text { Pré- } \\
\text { escola }\end{array}$ & 14.179 & 11.330 & 14.588 & 14.182 \\
\hline
\end{tabular}

FONTE: ROSA, 2005, p.216.

$\mathrm{Na}$ tabela 7 foi realizado o cruzamento dos dados populacionais e das matrículas. Diante disso, teve-se como dimensionar a demanda reprimida no município de Campo Grande. No período de 1991 e 2000 houve uma redução de 9,5\% da demanda reprimida na pré-escola, caracterizando um movimento de expansão.

Tabela 7 - Demanda reprimida na educação infantil no município de Campo Grande.

\begin{tabular}{|c|c|c|c|c|c|}
\hline \multicolumn{3}{|c|}{ Ano } & 1991 & 1996 & 2000 \\
\hline \multirow{3}{*}{ 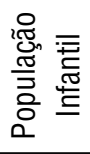 } & \multicolumn{2}{|c|}{0 a 6 anos } & 82.623 & 82.967 & 85.237 \\
\hline & \multicolumn{2}{|c|}{0 a 3 anos } & 47.093 & 46.956 & 46.956 \\
\hline & \multicolumn{2}{|c|}{4 a6 anos } & 35.530 & 36.011 & 38.281 \\
\hline \multirow{2}{*}{ 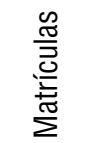 } & \multicolumn{2}{|c|}{ Creche } & --- & --- & 5.596 \\
\hline & \multicolumn{2}{|c|}{ Pré-Escola } & 10.663 & 14.216 & 14.234 \\
\hline \multirow{6}{*}{ 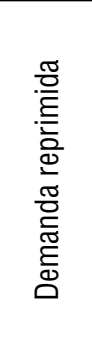 } & \multirow{2}{*}{$\begin{array}{l}0 \text { a } 3 \\
\text { anos }\end{array}$} & $\begin{array}{c}n^{\circ} \\
\text { absol. }\end{array}$ & --- & --- & 41.360 \\
\hline & & $\%$ & --- & --- & $88,08 \%$ \\
\hline & \multirow{2}{*}{$\begin{array}{l}4 \text { a } 6 \\
\text { anos }\end{array}$} & $\begin{array}{c}n^{\circ} \\
\text { absol. }\end{array}$ & 24.867 & 21.795 & 24.047 \\
\hline & & $\%$ & $70 \%$ & $60,5 \%$ & $62,81 \%$ \\
\hline & \multirow{2}{*}{$\begin{array}{l}0 \text { a } 6 \\
\text { anos }\end{array}$} & $\begin{array}{c}n^{\circ} \\
\text { absol. }\end{array}$ & --- & --- & 65.407 \\
\hline & & $\%$ & --- & --- & $76,73 \%$ \\
\hline
\end{tabular}

FONTE: Tabela elaborada a partir de dados da Estatística/SUPAE/ SED-MS e IBGE (censo 1991e 2000, contagem populacional 1996)

Já no período entre 1996 e 2000, a demanda reprimida cresceu $2,81 \%$, como se pode observar nos gráficos 10 e 11 : 
Gráfico 10 - Demanda reprimida na pré-escola na rede municipal de ensino de Campo Grande em 1996

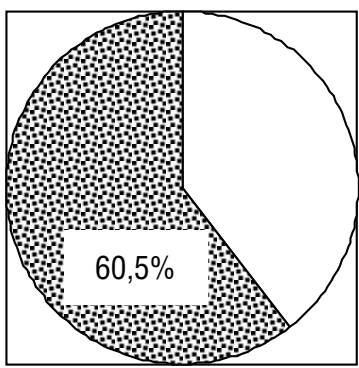

$\square$ Demanda atendida

Q Demanda Reprimida

FONTE: Gráfico elaborado a partir de dados da Coordenadoria de Estatística/SUPAE/SED-MS e IBGE (censo 1991e 2000, contagem populacional 1996).

Gráfico 11 - Demanda reprimida na pré-escola na rede municipal de ensino de Campo Grande em 2000

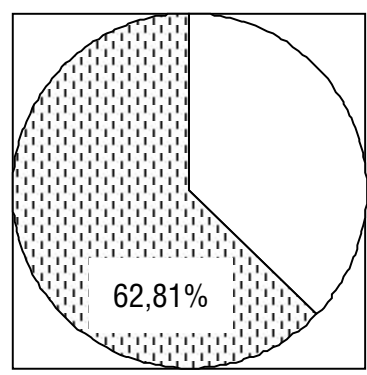

\begin{tabular}{|c|}
\hline Demanda \\
atendida \\
$\square$ Demanda \\
Reprimida \\
\hline
\end{tabular}

FONTE: Gráfico elaborado a partir de dados da Coordenadoria de Estatística/SUPAE/SED-MS e IBGE (censo 1991e 2000, contagem populacional 1996).

Sobre os dados da Educação Infantil (2000), a demanda reprimida foi maior, chegando a $76,73 \%$. Já na faixa etária de 0 a 3 anos este índice chega a 88,08\%, como mostraram os gráficos 12 e 13:

Gráfico12 - Demanda reprimida na educação infantil na rede municipal de ensino de Campo Grande em 2000

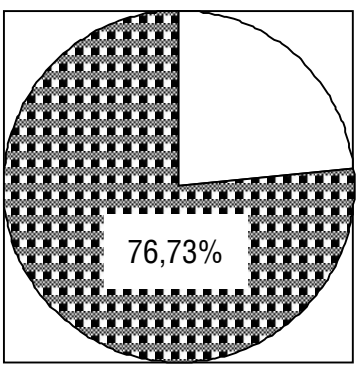

\begin{tabular}{|c|}
\hline Demanda \\
atendida \\
Demanda \\
reprimida \\
\hline
\end{tabular}

FONTE: Gráfico elaborado a partir de dados da Estatística/SUPAE/ SED-MS e IBGE (censo 1991e 2000, contagem populacional 1996).

Gráfico 13 - Demanda reprimida em creche na rede municipal de ensino de Campo Grande em 2000

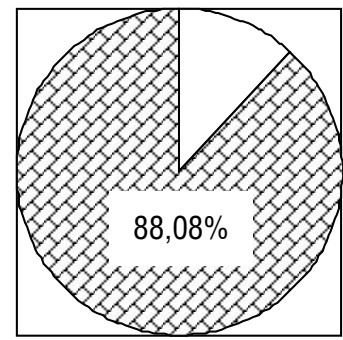

\begin{tabular}{|c|}
\hline Demanda \\
atendida \\
○ Demanda \\
reprimida \\
\hline
\end{tabular}

FONTE: Gráfico elaborado a partir de dados da Coordenadoria Estatística/SUPAE/SED-MS e IBGE (censo 1991e 2000, contagem populacional 1996).
Em 2000, das 85.230 crianças entre 0 e 6 anos do município de Campo Grande, apenas 19.830 frequentaram a educação infantil. Já na faixa de 0 a 3 anos das 46.956 crianças, somente 5.596 frequentaram as creches. Isto significou que de cada 100 crianças de 0 a 6 anos, apenas 23 frequentaram a educação infantil. E de cada 100 crianças de 0 a 3 anos, apenas 12 frequentaram creches.

Ficaram claros os impactos do FUNDEF sobre as matrículas e a demanda reprimida e na expansão da rede privada.

Importa agora verificar quais recursos financiaram a educação infantil no município de Campo Grande no período de 1997 a 2000, a partir dos balanços anuais do município.

Como mostra a tabela 8, em 1998, ano de implantação do FUNDEF, os gastos passaram de $\mathrm{R} \$ 2.785 .303,67$ para $1.634 .436,90$, uma redução de $70 \%$, portanto.

Tabela 8 - Despesas com educação infantil da rede municipal de Campo Grande (1997 a 2000)

\begin{tabular}{|c|c|c|c|c|}
\hline $\begin{array}{l}\text { Despesas } \\
\text { pré-escola }\end{array}$ & 1997 & 1998 & 1999 & 2000 \\
\hline Pessoal Civil & 95.885 & $1.291 .628,66$ & $1.852 .903,27$ & 2.026.833,96 \\
\hline $\begin{array}{l}\text { Obrigações } \\
\text { patrimoniais }\end{array}$ & $9.219,62$ & $84.465,99$ & $236.446,79$ & $307.701,19$ \\
\hline $\begin{array}{l}\text { Material de } \\
\text { consumo }\end{array}$ & $1.125 .918,16$ & $40.890,79$ & $43.315,18$ & $184.387,49$ \\
\hline $\begin{array}{l}\text { Remun. Sev. } \\
\text { Pessoais }\end{array}$ & ני-ב- & --י-- & --.-- & --.- \\
\hline $\begin{array}{l}\text { Outros Serv. } \\
\text { Encargos }\end{array}$ & $694.708,42$ & $4.491,28$ & $96.643,02$ & $28.324,62$ \\
\hline $\begin{array}{c}\text { Subvenções } \\
\text { Pessoais }\end{array}$ & - & יב-ב- & $\ldots$ & - \\
\hline Inativos & -- & ---- & ---- & ---- \\
\hline $\begin{array}{l}\text { Salário } \\
\text { Família }\end{array}$ & $4.700,70$ & $15.647,38$ & $1.062,04$ & 698,78 \\
\hline $\begin{array}{c}\text { Obras e } \\
\text { Instalações }\end{array}$ & $632.750,21$ & $197.312,80$ & 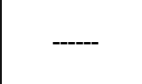 & $61.908,74$ \\
\hline $\begin{array}{l}\text { Equip. e mat. } \\
\text { Permanente. }\end{array}$ & $222.120,76$ & --- & $121.120,00$ & $55.395,58$ \\
\hline Total & $2.785 .303,67$ & $1.634 .436,90$ & $2.351 .490,29$ & 2.665.250,38 \\
\hline
\end{tabular}

FONTE: tabela elaborada a partir de dados extraídos dos Balancos Anuais de Contas de Governo do município de Campo Grande. Exercícios de 1996, 1997, 1998, 1999, 2000 e conferidos em ROSA, 2005, p. 214. 
Gráfico 14 - Despesas com pré-escola da rede municipal de ensino de Campo Grande (1997-2000)

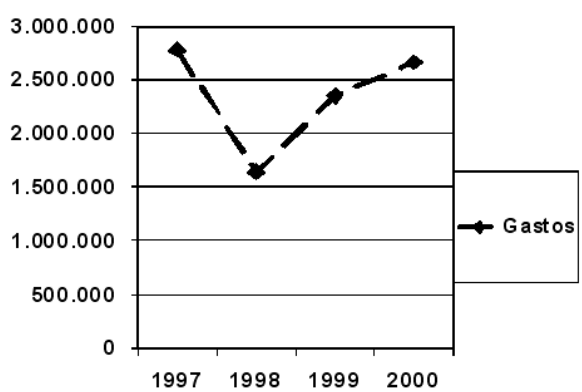

FONTE: tabela elaborada a partir de dados extraídos dos Balanços Anuais de Contas de Governo do Município de Campo Grande. Exercícios de 1996, 1997, 1998, 1999, 2000.

Esses números deixam claras uma penalização da educação infantil e a priorização do ensino fundamental. Conforme afirmou Rosa (2005, p.214):

Assim, posso dizer que a REME-Campo Grande, sempre priorizou o Ensino Fundamental e que essa prioridade se exacerbou com o Fundef, contrariando o dispositivo constitucional que indica o município como provedor desse nível educacional. Isso fica claro nos gastos com a El.

Apesar de os recursos terem aumentado nos anos posteriores, em 2000 o valor ainda era 4,32\% menor que no ano de 1997. Todos esses dados demonstraram um abandono da educação infantil e, consequentemente, das crianças. Abandono que se evidenciou ainda mais com a implantação do FUNDEF, cuja focalização de recursos foi para o ensino fundamental.

\section{Considerações finais}

Este trabalho desvelou o impacto que a implantação do FUNDEF causou na educação infantil do município de Campo Grande, em razão de que foi um fundo de natureza contábil que priorizou o ensino fundamental. Pode-se agora argumentar que este fundo foi a expressão de uma gestão governamental em âmbito federal na perspectiva do Estado gerencial, cuja gestão informava não existir problema de escassez de recursos para a educação, mas sim má distribuição, criando uma política de otimização e priorização desses recursos.

Essa dinâmica de priorização do financiamento do ensino fundamental imprimiu no Estado de Mato Grosso do Sul uma redução de $20,85 \%$ no total de matrículas na préescola entre os anos de 1997 e 1998 (ano de implantação nacional do FUNDEF). Porém, as matrículas das pré-escolas nas redes municipais cresceram 44,8\%, entre 1997 e 2000, refletindo o movimento de descentralização do ensino causado pelo Fundo.

Nas matrículas da pré-escola no Estado de Mato Grosso do Sul o maior impacto foi o fechamento das salas de pré-escolas da rede estadual. Houve uma diminuição de 87,17\% em todo o estado. Esta fuga foi justificada pela implantação do regime de ciclos que absorveria as crianças de seis anos no ensino fundamental. Contudo, as crianças de 4 e 5 anos que também frequentavam as pré-escolas deixaram de ser atendidas.

Ao analisar a demanda reprimida no Estado de Mato Grosso do Sul, entre 1996 e 2000, os índices são mais alarmantes. Em 2000 a demanda reprimida na pré-escola foi de $64,68 \%$. $\mathrm{Na}$ creche o índice foi de $91 \%$ e na educação infantil (creches e pré-escolas) a demanda reprimida foi de $79,48 \%$. Isto significou que em 2000, de cada 100 crianças, de até 3 anos de idade, apenas nove frequentaram creche (municipais, estaduais ou privadas, no Estado de Mato Grosso do Sul).

Quando se volta à análise para o município de Campo Grande, os números também demonstraram mudanças ocorridas na educação infantil a partir de 1998, ano de implantação do FUNDEF. No período de 1999 a 2000 houve uma diminuição de 909 matrículas na pré-escola da rede pública municipal. Nesse mesmo período a rede municipal teve um aumento de 842 matrículas na primeira série do ensino fundamental, situação que mostrou um movimento de priorização do ensino fundamental.

Outra evidência que os índices apontaram foi a expansão da rede privada no atendimento da pré-escola, já que o município e o estado diminuíram suas matrículas. No ano 2000 a rede privada atendeu 741 crianças a mais do que o município. Houve um crescimento de 6,9\% nas matrículas da rede privada de 1999 para o ano 2000. 
Quando se analisaram os recursos destinados pela Secretaria Municipal de Educação para a educação infantil, o impacto de recuo de atendimento se tornou ainda mais evidente em 1998, pois houve uma redução de $70 \%$ dos recursos. Nos anos seguintes, embora os recursos destinados fossem gradativamente aumentando, todavia, em 2000, esses recursos ainda eram 4,33\% menores do que em 1997.

Em se tratando da demanda reprimida para a educação infantil no município de Campo Grande, esta chegou em 2000 a 76,73\%. Na faixa etária de 0 a 3 anos este número chegou a $88,08 \%$. Isso significou que, nesse ano, de cada 100 crianças de até 3 anos no município de Campo Grande, apenas 12 frequentaram creches.

Importa refletir que, por mais que os números aqui apresentados não mostraram rostos, histórias ou sonhos, eles representaram as crianças que tiveram seu direto educacional negado. A educação infantil é um direito da criança, opção da família e um dever do Estado, que vem se eximindo desta obrigação. Este trabalho nunca poderá dimensionar os impactos que a falta de atendimento pode ter acarretado na vida de muitas dessas crianças.

Pontua-se que o financiamento para a manutenção e o desenvolvimento do ensino estabelecido pela Constituição Federal de 1988 em seu artigo 212, que criou a vinculação constitucional de recursos para o ensino de $25 \%$ da receita de impostos, reforça a composição do montante histórico que o Brasil tem dispendido para financiar o setor da ordem de $4 \%$ de seu Produto Interno Bruto (PIB) (PINTO, 2002). Este dado brasileiro quando comparado comos gastos de outros países no setor tem-se revelado como um dos menores gastos em termos percentuais do PIB na educação (PINTO, 2002). Apesar disso, a vinculação constitucional de recursos instituída permitiu, até a promulgação do FUNDEF, que estados e municípios operassem seu regime de colaboração com autonomia, de acordo com aquilo estabelecido pelo pacto federativo em vigor.

O FUNDEF, contudo, alterou as relações federativas entre as unidades federadas restringindo a possibilidade de autonomia relativa, na medida em que ele instituiu uma subvinculação constitucional de recursos, obrigando estados e municípios a gastarem $15 \%$ dos $25 \%$ da receita de impostos tãosomente em manutenção e desenvolvimento do ensino (MDE) no ensino fundamental. Isto porque as unidades federadas têm mantido o padrão histórico de transformar em patamar máximo aquilo que a legislação estabeleceu como mínimo (inclusive a União). Até a implantação do FUNDEF, estados e municípios poderiam operar variando os seus $25 \%$ da receita de impostos em manutenção e desenvolvimento do ensino o quanto quisessem deste percentual naquelas etapas da educação básica de sua competência e responsabilidade. A subvinculação constitucional de recursos (FUNDEF) Ihes retirou essa alternativa. A propósito, vale lembrar que tanto estados como municípios poderiam assegurar recursos a mais para o ensino, resgatando com isso a autonomia federativa.

Em 2007, com a substituição do FUNDEF pelo Fundo de Manutenção e Desenvolvimento da Educação Básica e de Valorização dos Profissionais da Educação (FUNDEB), embora o conceito contábil permaneça, bem como a política de fundos para financiar a manutenção e desenvolvimento do ensino, talvez a reengenharia produzida pelo FUNDEB venha em alguma medida beneficiar a educação infantil. Reforça-se o talvez por duas razões, em relação ao município de Campo Grande: a primeira é porque o preceito constitucional que mantém o financiamento para manutenção e desenvolvimento do ensino continua no patamar dos $25 \%$ da receita de impostos o que significa que não houve aumento de recursos para financiar a manutenção e o desenvolvimento de ensino na totalidade; a segunda é que um município com tal déficit histórico de atendimento a essa população dificilmente cumprirá sua parte no regime de colaboração instituído legalmente, caso não enfrente o desafio de investir para além dos $25 \%$ da receita de impostos em manutenção e desenvolvimento do ensino. 


\section{Referências}

BRASIL. Constituição da República Federativa do Brasil. São Paulo: Editora Revista do Tribunal, 2003.

Campanha Nacional de Credenciamento e Integração das Instituições e Educação Infantil aos Sistemas de Ensino. Brasília: MEC, 2005.

Lei 9.394, de 20 de dezembro 1996. Estabelece as Diretrizes e Bases da Educação Nacional. Brasília: Diário Oficial da União, 20-12-96.

Lei 9.424, de 24 de dezembro de 1996. Dispõe sobre o Fundo de Manutenção de Desenvolvimento do Ensino Fundamental e de Valorização do Magistério. Brasília: Diário Oficial da União, 24-12-96. abril.2007

INEP. Censo Escolar. Brasília: 1998. Disponível em: < http:// www.inep.gov.br/basica/censo/ Acesso em: abril.2007

INEP. Censo Escolar. Brasília: 1999. Disponível em: < http:// www.inep.gov.br/basica/censo/ Acesso em: abril.2007

INEP. Censo Escolar. Brasília: 2000. Disponível em: < http:// www.inep.gov.br/basica/censo/ Acesso em:

Manual de Orientação - Fundef. Brasília: MEC, 2005.

Política Nacional de Educação Infantil: pelo direito das crianças de zero a seis anos à Educação. Brasília: MEC, 2006.

CAMPO GRANDE. Secretaria Municipal de Fazenda. Balanços Anuais de Contas de Governo dos anos de 1997 a 2000.

Secretaria Municipal de Educação. Divisão de Estatística Educacional. Campo Grande, MS: anos de 1997 a 2000

DAVIES, N. O FUNDEF e orçamento da educação: desvendando a caixa preta. Campinas, SP: Editora Autores Associados, 1999.

DIDONET, V. Educação Infantil - Horizontes das políticas atuais. Brasília, DF: 1999.

GUIMARÃES, J. L; PINTO, J. M. R. A demanda pela Educação Infantil e os recursos disponíveis. Em Aberto, Brasília, v.18, n. 74, p.92-105, dez. 2001.

IBGE. Censo Demográfico de 1991 e 2000. Contagem populacional 1996.

MATO GROSSO DO SUL. Secretaria de Estado de Educação. Política Estadual para Educação Infantil. Campo Grande, MS: 2006 MS: 2007

Secretaria de Estado de Educação. Coordenadoria Geral de Estatísticas Educacionais. Campo Grande, MELCHIOR, J. C. A. Mudanças no financiamento da Educação no Brasil. São Paulo: Autores Associados, 1995

PINTO, J. M. R. Financiamento da Educação no Brasil: um balanço do governo FHC (1995-2002). CEDES, v. 23, n. 80, set. 2002, p. 108-135. Disponível em: < http://www.cedes.unicamp.br > Acesso em: jan.2007

ROSA, M. F. O direito da criança a ter direito: a Educação Infantil em Mato Grosso do Sul (1991-2002). Tese de Doutorado, FEUSP, 2005.

UNDIME. Relatório sobre o atendimento à educação infantil nos municípios brasileiros. Brasília, DF: 1999.

Recebido em maio de 2009.

Aprovado em junho de 2009. 